\title{
ELABORAÇÃO DE MATERIAL DIDÁTICO DE LÍNGUA PORTUGUESA COMO L2 PARA ALUNOS SURDOS DO CURSO DE PEDAGOGIA: DESAFIOS E POSSIBILIDADES
}

\author{
Fernanda Beatriz Caricari de MORAIS (Instituto Nacional de Educação de Surdos) \\ Osilene Maria de Sá e Silva da CRUZ (Instituto Nacional de Educação de Surdos) ${ }^{1}$
}

\begin{abstract}
Resumo: Este artigo apresenta uma reflexão sobre a construção do material didático de Língua Portuguesa como Segunda Língua para Surdos, desenvolvido para o curso de Licenciatura em Pedagogia com característica bilíngue a ser oferecido na modalidade online, para integrar o Programa "Viver sem Limite", do Governo Federal, visando formar pedagogos para atuarem no ensino e na gestão escolar, com enfoque na educação de surdos. Tendo em vista a importância do ensino de LP como L2 e a necessidade premente de elaboração de materiais didáticos eficazes para o ensino dessa língua para alunos surdos, esta pesquisa detalha o processo de elaboração de unidades didáticas do curso online, a partir do que sugerem os Parâmetros Curriculares Nacionais (BRASIL, 1998) sobre a importância do ensino de LP baseado em gêneros textuais e em pesquisas sobre ensino de LP para surdos (FERNANDES, 2002, 2004; QUADROS, 2005; QUADROS e SCHMIEDT, 2006; SALLES et al, 2004, entre outros). Os usos de recursos digitais e de tecnologias para a EAD desempenham um papel importante na elaboração de material didático para esses aprendizes, facilitando o processo de aprendizagem.
\end{abstract}

Palavras-chave: Educação a Distância; Material Didático; Língua Portuguesa para alunos surdos

\begin{abstract}
This article presents a reflection about the elaboration of didactic material for teaching Portuguese as a Second Language for deaf students, developed for Education undergraduation course, with bilingual features, that will be offered in an online context that is a part of "Viver sem Limite", a project from Federal Government. Considering the importance of teaching Portuguese as a second language and the necessity to produce effective didactic materials for teaching deaf students, this research describes the process for elaborating didactic units for an online course, following the National Curricular Parameters (BRASIL, 1998) on the importance of teaching Portuguese based on textual genres and on studies about teaching deaf students (FERNANDES, 2002, 2004; QUADROS, 2005; QUADROS e SCHMIEDT, 2006; SALLES et al, 2004, among others). The use of digital resources and technologies for online courses has an important role for didactic material for these learners, helping them in their learning process.
\end{abstract}

Keywords: Distance Education; Didatic Material; Portuguese for deaf students

\footnotetext{
${ }^{1}$ Doutoras em Linguística Aplicada e Estudos da Linguagem (PUC-SP). Professoras Adjuntas do Departamento de Ensino Superior do Instituto Nacional de Educação de Surdos (MEC/RJ).
} 


\section{Introdução}

Este artigo busca apresentar uma reflexão sobre elaboração de material didático para o ensino de Língua Portuguesa (LP) como L2 para alunos surdos, mais especificamente, buscamos destacar a importância do processo de elaboração de unidades didáticas para um curso online de Pedagogia do Instituto Nacional de Educação e Surdos - INES.

A pesquisa relatada aqui está inserida em um contexto maior, o do Grupo de pesquisa: Ensino de línguas e literaturas no ensino bilíngue de surdos ${ }^{2}$, cadastrado no CNPq, contando com a participação de professores, intérpretes, graduandos e pós-graduandos, voluntários e bolsistas, que têm como objetivo refletir sobre temas relacionados à educação de surdos e à elaboração de materiais didáticos com foco nas necessidades reais desses aprendizes.

O avanço dos recursos tecnológicos e a facilidade de acesso ao ambiente digital constituem importantes ferramentas que possibilitam troca de informações, independentemente do contato físico entre os participantes em suas interações sócio-educativas.

Dados da Associação Brasileira de Ensino a Distância (ABED) revelam que a história da Educação a Distância (EaD) no Brasil começou em 1904, por meio de um anúncio nos classificados do Jornal do Brasil com a oferta de curso de datilografia por correspondência. $\mathrm{O}$ Decreto $n^{\circ} 5.622 / 2005$, no Art. $1^{\circ}$ caracteriza a Educação a Distância como

modalidade educacional na qual a mediação didático-pedagógica nos processos de ensino e aprendizagem ocorre com a utilização de meios e tecnologias de informação e comunicação, com estudantes e professores desenvolvendo atividades educativas em lugares ou tempos diversos.(BRASIL, 2005)

No caso do presente artigo, mostraremos a trajetória de duas professoras diante do desafio de elaborar material didático para o ensino de LP como L2 para alunos surdos, dentro de um ambiente virtual, com aulas ministradas, sobretudo, em Língua Brasileira de Sinais - LIBRAS, a L1 do sujeito surdo. Buscamos atender de forma satisfatória o que estabelece o Decreto 5.626/2005 com relação ao uso da língua de sinais como instrumento de instrução aos aprendizes surdos. Ainda de acordo com o referido decreto, a Língua Portuguesa será ministrada na modalidade escrita, sendo considerada a segunda língua do sujeito surdo e não poderá ser substituída pela LIBRAS.

Dessa forma, além do desafio de elaborar material didático para um curso de graduação online, deparamo-nos, também, com a responsabilidade de trabalhar com a LP como L2, tendo a LIBRAS como língua de instrução. Nesse sentido, recorremos a vários estudiosos que tratam do ensino online e educação a distância - EaD (MORAN, 2005; MAIA e MATTAR, 2007, dentre outros) e do ensino de LP como L2 para aprendizes surdos (FERNANDES, 2002, 2004; QUADROS, 2005; QUADROS e SCHMIEDT, 2006; SALLES et al, 2004, entre outros)

$\mathrm{O}$ artigo está estruturado em seções, além da Introdução e das Referências. A próxima seção abordará um breve histórico sobre a Educação a Distância no Brasil.

${ }^{2}$ http://dpg.cnpq.br/dpg/espelhogrupo/8191336634503455 


\section{Breve histórico da Educação a Distância no contexto brasileiro}

EaD é a sigla empregada tanto para Educação a Distância quanto para Ensino a Distância (BELLONI, 2009) e, de acordo com Maia e Mattar (2007), sua trajetória no Brasil perpassa por três gerações:

$\checkmark$ A primeira geração, geração do ensino por correspondência, perdurou até a década de 1960. O Instituto Universal Brasileiro foi um dos principais proponentes de cursos profissionalizantes, como curso de mecânica de automóveis e outros cursos técnicos em geral. Os materiais eram impressos, sendo livros e apostilas.

$\checkmark$ A segunda geração, geração das novas mídias e universidades, teve início em 1970, com cursos disponibilizados por meio de vídeos, fitas cassetes, rádio e TV. O Telecurso é um exemplo dessa geração.

$\checkmark$ A terceira geração, geração EaD online, tem início nos anos 2000, com aulas ao vivo via satélite. Internet, MP3, ambientes virtuais de aprendizagem (AVA), vídeos, animações, ambientes $3 \mathrm{D}$, redes sociais e fóruns são exemplos de recursos utilizados nessa geração.

Moore e Kearsley (2008) acrescentam duas gerações: a quarta geração, da teleconferência; e a quinta geração, da internet/web.

Vivenciamos, atualmente, a grande propagação da $\mathrm{EaD}$, com oferta de vários cursos em diferentes modalidades e com diversas metodologias mais atualizadas, condizentes com a realidade dos alunos, cuja maioria tem acesso à internet, às redes sociais e utilizam os recursos tecnológicos (tablets, smartphones...) com bastante facilidade, sem a necessidade de grandes investimentos em tecnologia por parte da instituição e ensino. A EaD. Nesse sentido, atrai um público diversificado em termos de faixa etária e socioeconômica, camadas menos favorecidas socialmente, pois os alunos podem ajustar em sua rotina e em seu orçamento um curso de graduação, técnico ou tecnólogo.

De acordo com Maia e Mattar (2007),

O crescimento do mercado de educação a distância $(\mathrm{EaD})$ é explosivo no Brasil e no Mundo. Dados estão disponíveis por toda parte: cresce exponencialmente o número de instituições que oferecem algum tipo de curso a distância, o número de cursos e disciplinas ofertados, de alunos matriculados, de professores que desenvolvem conteúdos e passam a ministrar aulas a distância, de empresas fornecedoras de serviços e insumos para o mercado, de artigos e publicações sobre $\mathrm{EaD}$, crescem as tecnologias disponíveis, e assim por diante. (MAIA e MATTAR, 2007, p. xiii)

É importante ressaltar, entretanto, que cursos online demandam metodologias adequadas, professores com utilização de recursos audiovisuais interessantes e provocativos. Por outro lado, muitos anseios dos participantes devem ser levados em consideração, como a praticidade, menor rigidez nos horários de aula, possibilidade de execução e estudos a sem horário fixo e determinado. Essas facilidades, entretanto, não eximem o estudante de dedicação muito maior do que a do ensino presencial.

É importante a compreensão de que distanciamento físico entre os participantes "não implica distanciamento humano", conforme propõem Valente e Mattar (2007, p.19). Dessa forma, a instituição promotora de cursos online deve estar atenta a formas de promover interação entre os alunos e entre alunos e professores, num sentido interativo e dialógico. Os professores devem estar devidamente preparados em termos pedagógicos e tecnológicos para 
a EaD, para que não ocorra a "transposição" de aulas presenciais para ambientes online" (MAIA e MATTAR, 2007), o que pode implicar o subaproveitamento dos recursos disponíveis.

No caso apresentado neste trabalho, a equipe de professores do curso de Pedagogia online é orientada para elaborar unidades didáticas para alunos surdos e alunos ouvintes, e, mais especificamente, no caso da disciplina de Língua Portuguesa para alunos surdos, as Unidades Didáticas são elaboradas e postadas na plataforma, respeitando-se as singularidades dos alunos, pois as ementas e os conteúdos trabalhados são diferentes dos alunos ouvintes. Buscamos, nesse sentido, atender ao que está previsto no Decreto 5.626/2005, que regulamenta a Lei de LIBRAS (10.436/2002), no sentido de preparar os conteúdos e disponibilizá-los na plataforma em LIBRAS, primeira língua do sujeito surdo.

Além do professor conteudista, que elabora o material didático, o curso conta com intérpretes de Língua de Sinais para traduzir da LP para a LIBRAS e também atuar como interlocutores nas interações e provocar discussões durante a realização das atividades.

No caso específico deste trabalho, propomos uma reflexão sobre o ensino de LP para alunos surdos, dentro de um ambiente online e/ou virtual, que será apresentada a seguir.

\section{Ensino de Língua Portuguesa como L2 para surdos e os gêneros discursivos}

Sabe-se que o processo de ensino-aprendizagem de Língua Portuguesa como L2 depende do uso de metodologias adequadas que levam em conta as singularidades linguísticas dos surdos. Fernandes (2006), Pereira (2003), Quadros (1997) e Quadros \& Schmiedt (2006) argumentam que muitos aprendizes surdos são filhos de pais ouvintes e tiveram pouco ou nenhum contato com a LIBRAS e, por isso, tiveram experiências linguísticas pouco significativas. O letramento dos surdos, enquanto processo, faz sentido se significado por meio da LIBRAS, língua usada na escola para aquisição da L2 na modalidade escrita, que constitui suas funções sociais representadas no contexto brasileiro.

Com relação aos gêneros textuais, é consenso na comunidade acadêmica que são uma ferramenta poderosa no ensino de línguas, pois além dos estudos das escolhas linguísticas, ocorre aprendizagem de elementos verbais e não-verbais dentro da prática discursiva (ALMEIDA FILHO, 1997). Bronckart (2011) afirma que o gênero é o verdadeiro instrumento para o desenvolvimento das capacidades individuais, na perspectiva do interacionismo social, pois o sujeito sempre age utilizando a linguagem em uma determinada situação, com ajuda de uma ferramenta, o gênero textual (BAKHTIN, 1992).

Swales (1990) discute a concepção de gênero como eventos comunicativos, com propósitos compartilhados por membros de uma determinada comunidade discursiva. Dessa forma, os gêneros podem ser entendidos como:

(...) classes de eventos comunicativos que, tipicamente, possuem características estáveis e que podem ser reconhecidas. O gênero é um evento comunicativo que consiste de combinações escritas e/ou faladas, modeladas por aspectos ligados aos propósitos comunicativos e ao contexto de produção. (SWALES, 1990, p.09-10). 
O propósito comunicativo que motiva a realização do gênero é reconhecido por uma comunidade discursiva que o molda e o transforma, como apontam Swales (1990) e Bhatia (1997).

Dessa forma, entende-se e interpreta-se o significado das escolhas linguísticas de um texto a partir da caracterização do contexto de situação, dos participantes do evento e da interrelação entre contexto e participantes. Para Karnopp (2003), as práticas de leitura, análise e produção textual são concebidas como práticas sociais de linguagem, ligadas aos aspectos culturais, sociais, históricos e ideológicos. É preciso propor aos alunos uma reflexão que englobe o objetivo da produção, a relação entre leitor e autor, a identidade de quem produz (relações de poder, status, valores e atitudes).

O ensino deve, portanto, ser centrado em torno do texto, desenvolvendo as competências linguísticas, textuais e comunicativas. A escola sempre trabalhou com texto, porém, muitas vezes, restringe seus ensinamentos aos aspectos estruturais e formais. As práticas de leitura precisam ser contextualizadas, fornecendo condições para que o aprendiz surdo compreenda o texto. O professor deve, de acordo com Quadros \& Schmiedt (2006), provocar nos alunos o interesse pela leitura, fazendo discussões prévias sobre o assunto, utilizando estímulos visuais em suas aulas. É preciso pensar nas questões: qual o conhecimento que os alunos têm da temática abordada no texto? Como esse conhecimento pode ser explorado em sala de aula? Quais são as palavras fundamentais para a compreensão? Quais elementos linguísticos podem favorecer a compreensão? Dessa forma, o professor deve se pautar em estratégias que levem o aluno à compreensão de textos e de sua função social, identificando e diferenciando os tipos e as intenções de cada gênero discursivo abordado.

O processo de ensino-aprendizagem da leitura e da escrita para surdos é denominado por Fernandes (2006), de letramento, que toma essas habilidades como processos complementares e dependentes, inseridas em práticas sociais significativas. Há diferentes níveis de letramento, dependendo das necessidades do leitor/escritor em seu meio social e cultural. A referida autora (2003) propõe três eixos de trabalho com a linguagem escrita: 1) Aspectos funcionais; 2) Aspectos lexicais (vocabulário) e 3) Aspectos gramaticais (forma e estrutura). A base destes três eixos é a língua de sinais (base linguística). Os três eixos são apresentados abaixo:

1) Aspectos funcionais: Função social do texto (participantes, intenção), veículo de circulação, etc.;

2) Aspectos lexicais: as palavras só adquirem significados no contexto em que estão veiculadas. É importante sistematizar o vocabulário implicado no texto e sua intertextualidade com as leituras anteriores;

3) Aspectos gramaticais: aprender uma língua envolve conhecer a sua gramática, isto é, as regras de sua organização que permitem que seus usuários se entendam. Essas regras não são externas ao texto, mas são construídas internamente. $O$ foco não é, portanto, a gramática tradicional, mas o uso da língua.

Ler envolve compreensão global do texto, situando em determinada realidade social, fazendo parte de determinado gênero discursivo e atribuindo relações e efeitos de sentido entre as unidades que o compõe. Fernandes $(2003$, 2006) sistematiza uma proposta de encaminhamento metodológico no ensino de língua portuguesa como L2, colocando o trabalho com a leitura na centralidade das práticas de letramento em sala de aula.

A reflexão que se apresenta neste trabalho é decorrente da elaboração de material didático para um curso online de Pedagogia, com característica bilíngue, porque é oferecido 
em duas línguas: LIBRAS e LP. A seguir, será apresentado o Programa Viver sem Limite, que implementou oportunidades de educação às pessoas com deficiência no Brasil.

\section{Programa Viver sem Limite}

No ano de 2011, o Governo Federal lançou o Viver sem Limite ${ }^{3}$, um Plano Nacional dos Direitos da Pessoa com Deficiência, como resultado do firme compromisso político com a plena cidadania das pessoas com deficiência no Brasil, oportunizando direitos e cidadania para todas as pessoas. Ao lançar essa iniciativa, busca-se uma sociedade mais justa e plural para todos os brasileiros, especialmente aqueles que possuem alguma deficiência, o que representa $23,91 \%$ da população, ou cerca de 45,6 milhões de pessoas, como mostra o Censo 2010.

Segundo a proposta desse plano, só serão produzidas mudanças para a superação de limites quando equipararmos oportunidades entre pessoas com e sem deficiência, visto que os limites não são definidos pela condição de cada pessoa, mas pela sociedade, seja através de obstáculos físicos ou de atitudes preconceituosas.

Sabe-se que o acesso à educação é direito de todos, conforme a Constituição Federal (artigos $6^{\circ}$ e de 205 a 214), sem discriminação, em igualdade de oportunidades. Com base nessa afirmação, o plano Viver sem Limite investe em recursos e serviços de apoio à educação básica, por meio de implementação de salas de recursos multifuncionais, promoção de acessibilidade nas escolas, aquisição de materiais e a formação de professores. Este último investimento conta com a parceria do Instituto Nacional de Educação de Surdos (INES), responsável pela oferta do curso Pedagogia na perspectiva bilíngue (LIBRAS/Língua Portuguesa).

Para tornar realidade a educação bilíngue no Brasil, o Viver sem Limite prevê a criação de 27 cursos de Letras/LIBRAS - Licenciatura e Bacharelado - e 12 cursos de Licenciatura em Pedagogia com característica bilíngue, sendo criadas, por meio desse plano, 690 vagas para que as instituições federais de educação contratem professores, tradutores e intérpretes de LIBRAS.

O INES participa do plano Viver sem Limite, oferecendo o curso de Licenciatura em Pedagogia com perspectiva bilíngue para alunos surdos e ouvintes. A seguir, serão apresentadas algumas informações sobre o referido curso, cujas línguas de instrução são a LIBRAS e a Língua Portuguesa.

\section{O curso de Pedagogia do Instituto Nacional de Educação de Surdos (INES) no plano}

\section{Viver sem Limite}

O Plano Viver sem Limite possibilitou mudanças importantes, em especial para a educação de surdos, pois valoriza o uso da LIBRAS no ambiente educacional, busca a

\footnotetext{
${ }^{3}$ O Plano Viver sem Limites foi regulamentado pelo decreto 7.612/2011, disponível no endereço eletrônico: http://www.planalto.gov.br/ccivil_03/Ato2011-2014/2011/Decreto/D7612.ht. Acesso em 24 jun 2015.
} 
qualificação de professores para o ensino bilíngue e adaptações curriculares que tornem possível a inclusão do surdo na escola regular.

É importante destacar que desde 2004, o INES desenvolve ações para a implementação de curso superior de Pedagogia- Licenciatura Plena, que teve início presencialmente em 2006, no próprio INES, na cidade do Rio de Janeiro-RJ. A proposta do Plano Viver sem Limite é oferecer cursos de graduação, para atender uma demanda nacional, por isso, o INES criou o curso de Licenciatura em Pedagogia na modalidade bilíngue e online, em parceria com 12 instituições federais (Institutos e Universidades), abrangendo as cinco macrorregiões do Brasil, como se pode ver no quadro a seguir.

\begin{tabular}{|l|l|}
\hline \multicolumn{2}{|l|}{ Instituições/polos para oferta do curso online } \\
\hline IFG & Instituto Federal de Goiás \\
\hline IFPE & Instituto Federal de Pernambuco \\
\hline UEPA & Universidade Estadual do Pará \\
\hline UFAM & Universidade Federal do Amazonas \\
\hline UFBA & Universidade Federal da Bahia \\
\hline UFC & Universidade Federal do Ceará \\
\hline UFGD & Universidade Federal de Grande Dourados \\
\hline UFLA & Universidade Federal de Lavras \\
\hline UFPB & Universidade Federal da Paraíba \\
\hline UFPR & Universidade Federal do Paraná \\
\hline UFRGS & Universidade Federal do Rio Grande do Sul \\
\hline
\end{tabular}

Quadro 1: relação dos polos para o curso de Pedagogia online

O curso é pensado em uma perspectiva bilíngue, em que todo o material é disponibilizado em LIBRAS, sendo divulgado aos alunos por meio de vídeos, e em LP escrita, incluindo vários recursos disponíveis na plataforma, seguindo o manual do professorconteudista (INES, 2016, p. 12-14).

Pensando na importância de se proporcionar um ambiente de aprendizagem adequado aos alunos surdos, foi criada o Ambiente Virtual de Aprendizagem, o AVA, customizado para atender às necessidades e às exigências do público-alvo contemplado pelo curso de Pedagogia Bilíngue. Esse ambiente virtual dá suporte ao professor conteudista porque lhe permite muitas possibilidades para atender os aprendizes usuários de Língua Portuguesa e de LIBRAS e possibilita a inclusão de animações, vídeos, jogos, chats, fóruns e avatares.

Os professores conteudistas do curso são os docentes adjuntos no INES, que buscam desenvolver uma metodologia própria para o público do curso (surdos e ouvintes), utilizando o que há de mais atual no desenvolvimento de cursos online, em parceria constante com a comunidade surda para o desenvolvimento de uma formação pioneira e que leve em conta os anseios dos alunos surdos.

É importante mencionar que cada disciplina conta com dois professores-mediadores, sendo um Pedagogo e um professor de LIBRAS, que recebem as informações técnicas e teóricas de modo a conduzirem o curso, em contato, sempre que necessário, com o professorautor da disciplina. No desenvolvimento do curso e na atualização dos conteúdos na 
plataforma, os professores contam com o suporte de desenhistas instrucionais e webdesigners, parceiros na montagem, além de uma equipe técnica responsável pela manutenção do curso.

A avaliação dos alunos ocorre na modalidade online e presencial, sendo a presencial realizada no polo onde o curso é oferecido e ocorre ao longo da disciplina. Ao longo de cada unidade, o professor-mediador verifica se o aluno atingiu os objetivos previstos dentro do conteúdo trabalhado. Essa avaliação é definida pelo professor-autor e pode ser uma prova escrita, um trabalho em grupo, uma pesquisa ou outra estratégia que o professor preferir.

O curso é disponibilizado ao aluno por meio de uma plataforma, com várias informações que o levam ao conteúdo e às atividades propostas. Essa plataforma é constituída por alguns recursos pedagógicos, como segue:

Quadro 2: recursos disponíveis na plataforma do curso online.

\begin{tabular}{|l|l|}
\hline \multicolumn{1}{|c|}{ Recursos disponíveis } & \multicolumn{1}{|c|}{ Síntese } \\
\hline Chats & $\begin{array}{l}\text { são as conhecidas salas de bate-papo, em que os atores do } \\
\text { processo poderão se comunicar ao longo do curso. Há, } \\
\text { também, opção de chamadas por meio de vídeos. }\end{array}$ \\
\hline Fóruns & $\begin{array}{l}\text { tópicos de discussões orientadas, com propostas de atividades } \\
\text { a serem cumpridas. Essa ferramenta possibilita a postagem de } \\
\text { vídeos em LIBRAS, língua com a qual muitos dos alunos se } \\
\text { sentem mais à vontade. }\end{array}$ \\
\hline Mapa mental & $\begin{array}{l}\text { uma rede de mapas conceituais, em que os alunos e os } \\
\text { professores desenvolvem todos os conteúdos trabalhados em } \\
\text { cada unidade do curso de forma dinâmica. }\end{array}$ \\
\hline $\begin{array}{l}\text { PLE (Personal Learning } \\
\text { Environment - Ambiente } \\
\text { pessoal de aprendizagem) }\end{array}$ & $\begin{array}{l}\text { uma rede social própria, em que cada aluno é responsável por } \\
\text { publicar conteúdos que agreguem valor ao material } \\
\text { trabalhado em cada disciplina, trazendo informações e } \\
\text { discussões próprias e criando uma grande rede de } \\
\text { aprendizagem com outros alunos e professores, de dentro e de } \\
\text { fora do curso. }\end{array}$ \\
\hline
\end{tabular}

Quadro 2: alguns recursos disponíveis na plataforma

O material proposto pelos professores-autores é trabalhado e acompanhado por desenhistas instrucionais (DIs) que fazem parte da equipe e são responsáveis por moldar cada disciplina. A linguagem é um importante recurso que deve atingir o aluno de uma forma ao mesmo tempo amigável, estimuladora e respeitosa, tornando a aprendizagem uma experiência agradável e eficaz dentro das propostas desenvolvidas no curso.

Há de se atentar para a utilização da linguagem não verbal utilizada de forma bastante intensa, explorando os recursos visuais e a variedade comunicativa, pois se trata de um curso bilíngue, o que exige um foco no visual, no imagético. Por isso, pensando na importância de recursos e de estratégias adequadas para a educação de surdos, mais especificamente, na aprendizagem e no aprimoramento da Língua Portuguesa escrita, a próxima seção tece algumas considerações sobre materiais autênticos para o ensino de LP escrita para surdos.

\section{Elaboração do material didático para um curso online}


A elaboração do material didático deve partir de uma orientação com relação ao público-alvo de determinada disciplina e dos objetivos a serem atingidos. A experiência relatada neste artigo refere-se à disciplina de Língua Portuguesa como L2 para alunos surdos do curso online de Pedagogia. O currículo de LP desse curso apresenta características peculiares porque as turmas de alunos ouvintes e surdos são separadas e a ementa dessas disciplinas são elaboradas de forma a atender especificamente à especificidade de cada grupo de graduandos, de acordo com o quadro a seguir.

\begin{tabular}{|l|l|}
\hline \multicolumn{2}{|c|}{ Curso de Pedagogia do INES } \\
\hline \multicolumn{2}{|c|}{ Disciplina de Língua Portuguesa } \\
\hline Currículo antigo & Currículo atual (presencial e EaD) \\
\hline Turmas mistas (surdos e ouvintes) & Turmas separadas (surdos/ ouvintes) \\
\hline Ementa única para surdos e ouvintes & Ementas distintas para surdos e ouvintes \\
\hline LP I a LP VII & LP I a LP IV \\
\hline
\end{tabular}

Quadro 3: apresentação da Disciplina de LP no INES

O ambiente virtual de aprendizagem (AVA) é materializado por uma plataforma. Cada disciplina é constituída por 07 unidades e cada unidade deve ser pensada pelo professor conteudista para conter os seguintes fomentos:

- Roteiro com a apresentação da unidade: esse roteiro apresenta cada unidade e deve ser interativo e atrativo para os alunos. Além da apresentação em LP escrita, o roteiro é interpretado em LIBRAS, com o uso de recursos imagéticos e visuais;

- Dois textos-base com perguntas instigadoras e possíveis para debate: os textos trazem informações sobre o conteúdo da unidade e a seguir perguntas abertas que possibilitem discussões em fóruns e debates, mediados pelo professor tutor/mediador;

- Três objetivos: os objetivos devem ser pensados de forma que, ao final da unidade, o aluno esteja apto para cumprir determinada tarefa ou deter conhecimento sobre o conteúdo abordado na unidade;

- Temas para chat: o professor deve pensar em temas que gerem discussões entre os alunos e, nesse caso de grupo de alunos surdos, as discussões serão realizadas preferencialmente em LIBRAS, L1 dos participantes;

- Sites para instagrok: o professor conteudista deve propor nove sites que serão acessados e utilizados pelo professor tutor/mediador em discussões nos fóruns e nos chats. Servem como recursos complementares e com informações adicionais tratando do conteúdo, do gênero estudado, de filmes, vídeos, outros textos...;

- Vídeo 2 minutos: esse vídeo tem por finalidade trazer explicação sobre o conteúdo abordado naquela unidade, por exemplo, se o assunto for o gênero historia em quadrinhos, o vídeo pode ser um resumo sobre o gênero, com explicações;

- Atividade em grupo: das sete unidades que fazem parte de uma disciplina, quatro delas devem ter uma proposta para atividade em grupo, realizada de forma presencial em um sábado agendado com a coordenação do curso;

- Glossário: o glossário deve conter explicação de vocábulos usados na unidade para facilitar a compreensão do aluno. Não precisa ser, necessariamente, termos teóricos ou técnicos, mas também palavras importantes ou de sentido ambíguo que possam causar dúvida nos alunos; 
- Resumo expandido: esse resumo traz informações mais aprofundadas do tema abordado na unidade, com recursos: sinopse, filme, trailer. O objetivo é oferecer ao aluno o máximo de informações possível para que ele não leve dúvida para as unidades posteriores;

- Outros recursos: esses recursos podem vir em forma de jogos ou atividades interativas para possibilitar mais informação ao aluno.

Cabe ressaltar a importância de se retomar o assunto abordado na unidade anterior, quando da apresentação de uma unidade nova, pois possibilita resgatar o conteúdo trabalhado. Da mesma forma, consideramos importante que o ensino baseado em gêneros discursivos seja colocado em prática, pois possibilita que o aprendiz tenha acesso ao texto a partir de sua função sócio-comunicativa, de sua estrutura, dos objetivos e público-alvo.

Questões lexicogramaticais devem ser trabalhadas após a compreensão dos textos, após desenvolver as habilidades de leitura, lembrando que a escrita em LP deve ser posterior ao processo de compreensão textual. A leitura é um instrumento poderoso para o ensino, favorecendo o aprendizado de uma língua de forma rápida e eficiente. É importante que o professor estimule a leitura, use estratégias para que o aluno busque informações, ative seu conhecimento prévio, sua bagagem linguística e o conhecimento de mundo (QUADROS, 1997). Na plataforma, o ambiente reservado para outros recursos pode ser adequado para o ensino de aspectos gramaticais e a produção escrita, sendo, sempre necessária a presença do professor mediador para sanar as dúvidas e participar de forma ativa da aprendizagem do aluno.

As atividades devem ser pensadas e executadas em LIBRAS porque é a L1 do aluno, por meio da qual o aluno tem mais facilidade para se expressar, detém repertorio linguístico para formular suas frases e textos e consegue encadear as ideias de forma mais coerente. Outros recursos - trabalhar questões de uso da língua, por exemplo, apresentar uma unidade didática ou objeto de aprendizagem.

\section{Considerações finais}

Este trabalho teve como objetivo tecer algumas reflexões e considerações sobre elaboração de material didático para graduandos surdos do curso de Pedagogia em um contexto de ensino a distância. O diferencial da reflexão é a preocupação no sentido de que o material deve ser criado com objetivo específico, por isso, com conteúdos específicos que atendam as necessidades desses alunos, recorrendo à LIBRAS como sua primeira língua e entendendo a LP como sua L2.

Esse curso, oferecido na modalidade a distância, busca oportunizar uma proposta de ensino bilíngue, ampliando, dessa forma, a oportunidade para interessados em formação pedagógica para atuarem na Educação Infantil e nas series iniciais do Ensino Fundamental. A plataforma utilizada para a oferta do curso consiste em um ambiente interativo, em que o aprendiz pode recorrer a várias fontes de informação sobre as disciplinas do curso: os ambientes (textos, fóruns, chats, resumos, encontros presenciais e online...), o professor tutor/mediador, profissionais preparados para a montagem e apresentação do curso (webdesigners, intérpretes...) e a possibilidade de navegar no AVA com autonomia. 
Por fim, consideramos importante destacar que o curso online deve ser pensado e planejado com o intuito de atrair o aluno e mantê-lo envolvido nas atividades. Transferir conteúdos abordados em um curso presencial para um curso online não indica sucesso, pois é preciso envolvimento e interação entre professor e aluno, motivação para que o aprendiz exponha suas dúvidas e participe de forma ativa.

\section{Referências}

ALMEIDA FILHO, J.C.P. A Abordagem Orientadora da Ação do Professor. In: Parâmetros Atuais para o Ensino de Português Língua Estrangeira. Campinas: Pontes, 1997. p. 151. BAKHTIN, M. A Estética da criação verbal. São Paulo: Martins Fontes, 1992.

BHATIA, V. K. The Power and Politics of Genre. World Englishes, v. 16, n. 3, p. 359-371, Nov. 1997.

BELLONI, M. L. Educação a Distância. 5a Edição. Campinas: Autores Associados, 2009. BRASIL.Lei ${ }^{\circ}$ 10.436, de 24 de abril de 2002. Dispõe sobre a Língua Brasileira de Sinais - LIBRAS e dá outras providências. Disponível em:〈http:www.planalto.gov.br > Acesso em: 07.01.2015.

BRASIL. Decreto $\mathrm{N}^{\circ}$ 5.626. Regulamenta a Lei $\mathrm{n}^{\mathbf{0}} \mathbf{1 0 . 4 3 6}$, de 24 de abril de 2002, que dispõe sobre a Língua Brasileira de Sinais - LIBRAS, e o art. 18 da Lei ${ }^{\circ}$ 10.098, de 19 de dezembro de 2000. Publicada no Diário Oficial da União em 22/12/2005.

BRONCKART, J. P. The language system at the heart of the systems that make up the human being. Plenary session at the International Systemic Functional Congress, Faculty of Letters, University of Lisbon, Portugual, 2011.

FERNANDES, S. Educação bilíngue para surdos: identidades, diferenças, contradições e mistérios. Curitiba, 2003. Tese (Doutorado em Letras), Universidade Federal do Paraná.

FERNANDES, Sueli. Departamento de Educação Especial: área da surdez, 2002. Disponível em :http://www.diaadiaeducacao.pr.gov.br. Acesso em: 15/05/2012.

Educação Bilíngüe para Surdos: trilhando caminhos para a prática pedagógica. Curitiba: SEED/SUED/DEE, ago. 2004.

Práticas de letramento na educação bilíngue para surdos. Curitiba: SEED/SUED/DEE, 2006.

INSTITUTO NACIONAL DE EDUCAÇÃO DE SURDOS. Manual do Professor-autor. Rio de Janeiro: INES, 2016.

KARNOPP, Lodenir. Língua de sinais e língua portuguesa: em busca de um diálogo. In: LODI, Ana Claudia Balieiro et. al. (orgs.). Letramento e minorias. Porto Alegre: Mediação, 2003.

MAIA, C. e MATTAR, J. ABC da EaD: educação a distância hoje. São Paulo: Pearson Prentice Hall, 2007.

MOORE, M. e KEARSLEY. Educação a Distância: uma visão integrada. São Paulo: Cengage Learning, 2008.

MORAN, J. M. Tendências da educação on-line no Brasil In: RICARDO, Eleonora Jorge (Org.). Educação Corporativa e Educação a Distância. Rio de Janeiro: Editora Qualitymark, 2005.

PEREIRA,M.C.C. Papel da língua de sinais na aquisição da escrita por estudantes surdos. In: LODI, A.C.B.; HARRISON, K.M.P.; CAMPOS, S.R.L.; TESKE, O Letramento e minorias. Porto Alegre: Editora Mediação, 2002.

Paulo, 2003.

Leitura, escrita e surdez. São Paulo: Secretaria de Educação do Estado de São 
QUADROS, R. M. Educação de surdos: a aquisição da linguagem. Porto Alegre: Artmed,1997.

O 'Bi' em Bilinguismo na educação de surdos. In E. Fernandes (org.) Surdez e Bilinguismo. Porto Alegre: Editora Mediação, 2005. p. 26-36.

QUADROS, R. M., SCHMIEDT, M. L. P. Ideias para ensinar português para alunos surdos. Brasília: MEC, SEESP, 2006.

SALLES, H. M. M. L. et al. Ensino de língua portuguesa para surdos: caminhos para a prática pedagógica. Brasília: Ministério da Educação, Secretaria de Educação Especial, 2007, vol. 2, $2^{\mathrm{a}}$ ed.

SWALES, J. M. Genre Analysis: English in Academic and Research Settings. Cambridge (UK); New York: Cambridge University Press, 1990.

VALENTE, C. e MATTAR, J. Second Life e Web 2.0 na Educação: o potencial revolucionário das novas tecnologias. São Paulo: Novatec, 2007. 